\title{
Polymorphism: The Phenomenon Affecting the Performance of Drugs
}

\author{
Kaisar Raza ${ }^{1 *}$, Pramod Kumar ${ }^{1}$, Shanti Ratan ${ }^{1}$, Ruchi Malik ${ }^{1}$ and Shweta Arora ${ }^{2}$ \\ ${ }^{1}$ Department of Pharmacy, School of Chemical Sciences \& Pharmacy, Central University of Rajasthan, Bandar Sindri, India-305817 \\ ${ }^{2}$ Central Scientific Instruments Organization, Chandigarh, India-160030
}

Received: June 02, 2014, Accepted: July 17, 2014, Published: July 28, 2014

*Corresponding author: Kaisar Raza, Assistant Professor, Department of Pharmacy, School of Chemical Sciences \& Pharmacy, Central University of Rajasthan, Rajasthan, India, 305817; E-mail: drkaisar@curaj.ac.in; razakaisar_pharma@yahoo.co.in

\begin{abstract}
Polymorphism is the ability of solid materials to exist in two or more crystalline forms with different arrangements or conformations of the constituents in the crystal lattice. These polymorphic forms of a drug differ in the physicochemical properties like dissolution and solubility, chemical and physical stability, flowability and hygroscopicity. These forms also differ in various important drug outcomes like drug efficacy, bioavailability, and even toxicity. Polymorphic studies are important as a particular polymorph can be responsible for a particular property which might not be exhibited by any other form. This review will discuss the applied nature of polymorphism starting from their preparation, characterization and pharmaceutical importance with a special emphasis on drugs.
\end{abstract}

Keywords: Crystal forms, Crystallization, Raman spectroscopy, XRD, Crystallography

\section{Introduction}

The term polymorph has been derived from a Greek word "poly", which means "many", and "morph" "implying "form"”. Hence, polymorphism refers to different structural forms of a chemical substance. It is defined as the ability of a solid material to exist in two or more crystalline forms with different arrangements or conformations in the crystal lattice. More than $50 \%$ of active pharmaceutical ingredients (APIs) are estimated to have more than one polymorphic form $[1,2]$. Polymorphism and pseudomorphism are very common amongst drugs and are responsible for differences in many properties [3]. Generally, polymorphism is considered to be of two types, viz. monotropic systems and enantiotropic systems. In the former type, only one polymorphic form is stable at the temperatures below the melting point of the solid drug. However, in the latter, no such phenomenon is observed, though different forms can be stable than the others irrespective of any noticeable temperature pattern. These forms exhibit a temperature, where two polymorphic forms have same free energy, termed as transition temperature [4,5]. Though chemically same, the polymorphs have different lattice structures and subsequently differ in the physicochemical properties. Table 1 enlists various physiochemical and pharmaceutical properties, which are the functions of polymorphism of the APIs [6].
For the compounds exhibiting polymorphism, the knowledge of the thermodynamic stability and thermokinetics is desired for the better understanding of the transformations and the time span required for these transformations [7]. Existence of two basic polymorphic forms, viz. monotropes and enantiotropes is assumed on these bases. The relative stability and driving force for the polymorphic transformations at constant temperature and pressure is determined by Gibbs free energy $(\Delta G)$; the internal energy available for chemical work [8], as portrayed by equation 1 :

$$
\Delta G=\Delta H-T \Delta S
$$

Where $\Delta \mathrm{H}$ signifies the enthalpy change, while $\Delta \mathrm{S}$ accounts for the entropy change. Negative value of $\Delta \mathrm{G}$ assures the spontaneity of the polymorphic transitions, whereas the positive value renders the process non-spontaneous. Figure 1 depicts the influence of various thermokinetic and thermodynamic parameters on the molecular attributes resulting in polymorphic transitions. The graphs between $\Delta G$ versus temperature give the quantitative information about the stability of polymorphs. The former can be easily extracted from various studies viz. melting point, enthalpy of transformation (if available), enthalpy of fusion, and the van't Hoff plots. The data obtained from melting point is relatively easy to generate as it requires less quantity of the substance vis$\grave{a}$-vis the van't Hoff solubility studies. On contrary, it also poses the challenge of potential chemical degradation induced by high temperature. The latter method offers the advantage of studying the possibility for solution-mediated transformations or solvate formation during solubility measurement over a considerable temperature range and various solvent systems [8-10].

Pseudopolymorphs, i.e., co-crystals are also studied along with polymorphism, which are solid crystalline materials comprising two or more molecules or atoms in the same crystal lattice [11]. Co-crystals are also generally characterized as hydrates (solvent trapped), solvates (solvent present), and clathrates (molecules trapped) [12]. The first co-crystals reported were the co-crystals of hydroquinone and quinone in 1844 by Friedrich Wöhle [13]. Co-crystals directly affect the solid-state properties in terms of solubility and bioavailability. Co-crystals are frequently designed 


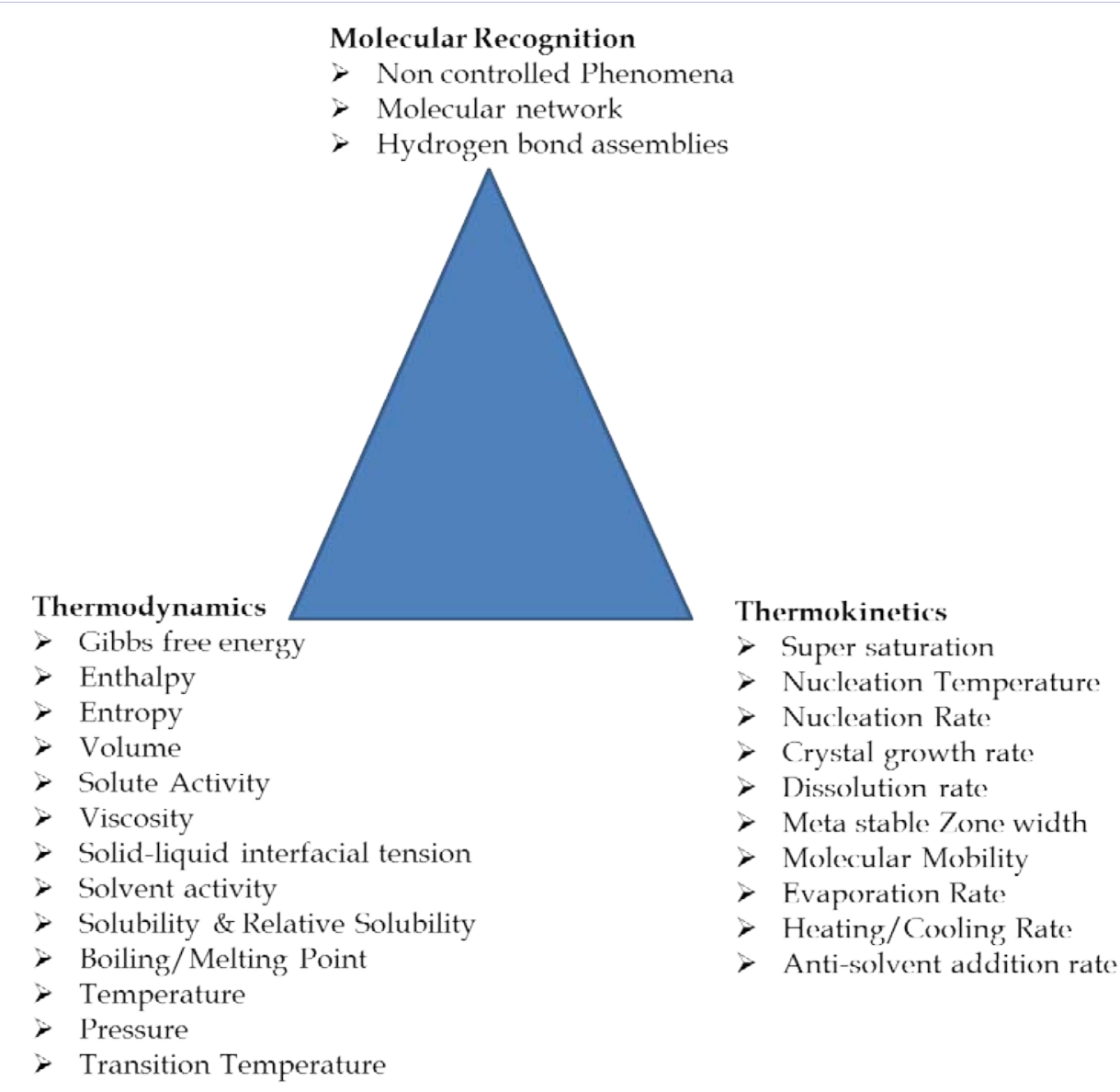

Figure 1: Pictorial representations of the inter-relationship of the thermodynamic and thermokinetic parameters on the solid-state transformations[8].

for pharmaceutical formulations and many pharmaceutical products like tropomyosin and troponin, have been already designed by virtue of the co-crystal phenomenon [14]. For better understanding, various solid state arrangements pertinent to polymorphs and co-crystals have been portrayed in Figure 2. The stereochemistry of the polymorphs and pseudopolymorphs is also a crucial parameter. The molecular dissymmetry and chirality associated is now being employed in the pharmaceutical drug development. Racemic mixtures are frequently characterized by their melting point phase diagram [15]. Each optically active compound has different pharmacological activity and it has been proved that chirality with dissymmetry, directly affects the pharmacological activity [16].

The difference in the thermodynamic, as well as other properties of various polymorphs, ranges from minute to significant difference; implying the various degrees of transformation of one form to another. The metastable forms are thermodynamically unstable and can easily transform to the low energy and thermodynamically stable forms. Henceforth, it is crucial to perform suitable polymorphic selection for each active pharmaceutical ingredient (API) and select the most stable polymorph for the product development. The most stable polymorph should be employed in the marketed formulation to prevent polymorphic alterations during manufacturing, delivery, or storage. In general, the selected polymorph should be thermodynamically stable during the drug development process and remain stable during the manufacturing process too [17]. In this context, various federal agencies require the appropriate description of the solid state of the API employed in the formulation [18]. Table 2 illustrates a few drugs whose polymorphic forms have been analyzed.

As far as dosage form development is concerned, following general rules are advised for the APIs which show polymorphism: (a) Selection of the lowest energy polymorph as it is the most thermodynamically stable form; (b) Avoidance of the metastable forms, though they are more physically stable, but chemically less stable. Attempts should be made to play with the excipients to achieve the set pharmaceutical goals, instead of selecting the metastable form; (c) Maintenance of such conditions which will avoid transitions from metastable form to the stable form throughout the shelf-life of the product, if the former form is selected due to a particular reason like bioavailability enhancement; (d) Assurance of avoidance of any polymorphic transition in the dosage form throughout its shelf-life, if so, the 


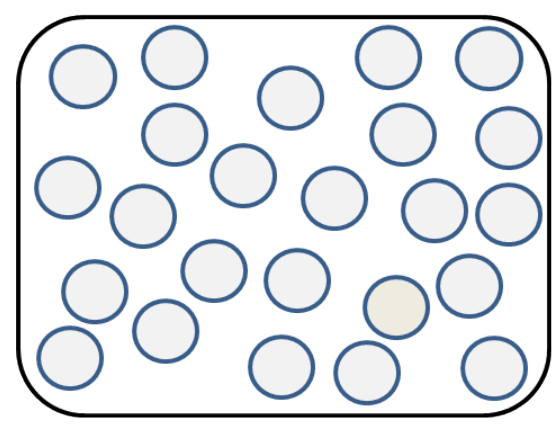

(a)

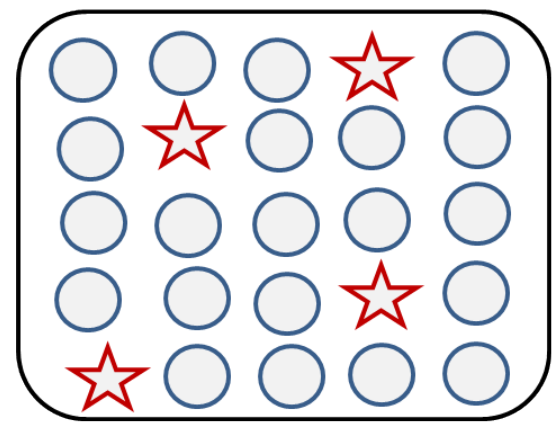

(c)

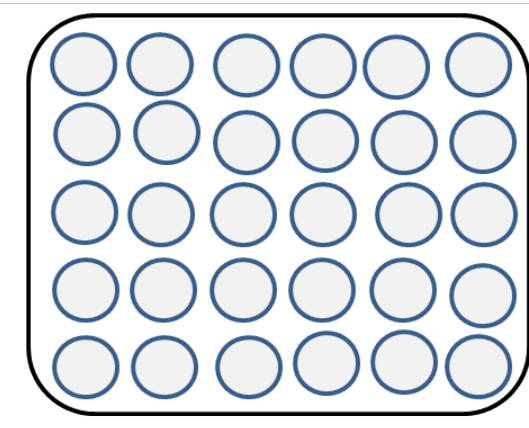

(b)

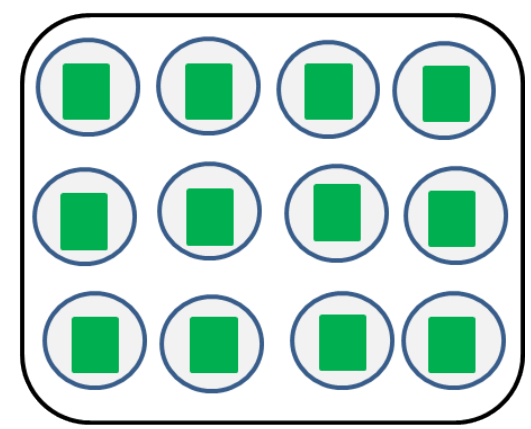

(d)

Figure 2: Pictorial representation (a) Amorphous form (b) Crystalline form (c) Hydrates and Solvates (d) Clathrates $\bigcirc$ Drug molecule $i$ Solvent molecule $\bigcirc$ Trapped drug molecule

same should not significantly affect the product quality and bioavailability [19,20].

\section{Methods of Polymorph Preparation}

Most of the polymorphic transitions occur spontaneously or by induction of some specific conditions, and generally require a complete solid-state characterization of the API and the excipients. Now-a-days, there is an increased interest between the formulation and medicinal scientists to explore the various possibilities of the polymorphic transitions in-situ and ex-formulation, generally as a component of preformulation studies. Therefore, many new methods have been investigated to induce the polymorphic transitions and this section will discuss a few most employed ones in brief. Figure 3 highlights the frequently reported methods for the polymorphic transitions in the APIs or so-called methods to prepare polymorphs.Most of these methods are neither novel nor new, but extension of the routinely employed crystallization techniques for various organic molecules including proteins. Table 3 provides a general comparison between these methods for a quick reference.

\section{Solvent evaporation method (Rota evaporation)}

In this approach, the saturated solution of the drug is prepared in an appropriate solvent and the solvent is removed by rotatory evaporation. Air drying at various temperatures, can also be employed to obtain different potential polymorphs [41].

\section{Slow cooling approach}

This technique is frequently employed for the polymorphic forms of less soluble drugs in the solvent systems having boiling point range of 30 to $90^{\circ} \mathrm{C}$. In brief, the solute is heated in the solvent just above the boiling point of the latter to produce the saturated solution. This solution is transferred to a stoppered tube and is connected to a Dewar flask containing water at a temperature just below the boiling point of the solvent. The Dewar flask is left in these conditions for several days. This technique may further be improved to obtain better crystal forms using different solvent mixtures of different polarities. Variation in the solvent composition may inhibit or promote growth of particular crystal faces and hence, can yield crystals of

Table 1: Physicochemical and Pharmaceutical Properties of APIs influenced by Various Polymorphic Forms.
*rystal habit, Morphology, Hygroscopy, Tabletability
* Refractive index/Optical properties/Melting point
*nthalpy, Spectral vibrational transitions
* Dissolution rate, Molar volume and density
Stability, Compatibility, Hardness, Intrinsic solubility
* Handling, Flowability, Blending, and Bioavailability 
the desired morphology. This approach is also called the solution growth approach $[42,43]$.

\section{Solvent diffusion technique}

This method is employed when the amount of drug available is less, and the drug is sensitive to air and/or solvent(s). In this option, the solution is placed in a sample tube; subsequently a less dense solvent is carefully dripped down the sides of the tube using either a pipette or a syringe to form a discreet layer. The slow diffusion of the solvent results in the crystallization of API at the interface. Most employed solvent combination is $\mathrm{CH}_{2} \mathrm{Cl}_{2} /$ ethanol and is preferred one, provided the sample is insoluble in ether [44].

\section{Vapor diffusion method}

This method is analogous to the previous one and is also applicable for the less quantities of the sample. In this case, the concentrated drug solution $(0.5 \mu \mathrm{L}$ to approximately $20 \mu \mathrm{L})$ is placed as a drop hanging on the underside of a microscope cover slip. The cover slip with the hanging drop is sealed with

Table 2: List of Various Drugs Studied for Polymorphism [21-50].

\begin{tabular}{|c|c|c|c|c|}
\hline S. No. & Name of the API & $\begin{array}{c}\text { Number of } \\
\text { Polymorphic forms }\end{array}$ & Bioavailable form & Advantages and significance \\
\hline 1 & Cortisone acetate [21] & 5 & I & Stable \\
\hline 2 & Methylprednisolone [22] & 2 & I & Higher dissolution \\
\hline 3 & Sulphamethoxydiazine [23] & 3 & III & Water stable form \\
\hline 4 & Chlortetracycline [24] & 2 (alpha and beta form) & Beta form & Absorbs faster in GIT \\
\hline 5 & Phenylbutazone [25] & 5 & IV & Most stable form \\
\hline 6 & 6-Mercaptopurine [26] & 3 & III & $\begin{array}{l}\text { Absorbs more efficiently from } \\
\text { GIT in comparison to form I }\end{array}$ \\
\hline 7 & Amobarbitol [27] & 2 & II & Dissolution rate is high \\
\hline 8 & Metoprolol tartrate [28] & 2 & I \& II & $\begin{array}{c}\text { Better tabletability, } \\
\text { compressibility and stability }\end{array}$ \\
\hline 9 & Phenobarbitone [29] & 6 & I, II, IV(Form D), VI & More stability \\
\hline 10 & Tolbutamide [30] & 4 & II and IV & $\begin{array}{l}\text { High solubility, dissolution and } \\
\text { oral absorption }\end{array}$ \\
\hline 11 & Furosemide [31] & 2 & I & Photochemical stability \\
\hline 12 & Carbamazepine [32 - 34] & 3 & I and III & Less degradation \\
\hline 13 & Phenobarbital [35] & 6 & $\mathrm{~A}, \mathrm{~B}$ and $\mathrm{F}$ & More stability \\
\hline 14 & Paracetamol [36-38] & 2 & II & $\begin{array}{c}\text { Good compressibility and plastic } \\
\text { deformation properties }\end{array}$ \\
\hline 15 & Cimetidine [39] & 4 & I and III & $\begin{array}{l}\text { Thermodynamically more } \\
\text { stable, Higher dissolution rate of } \\
\text { polymorphs III vis-à-vis form I }\end{array}$ \\
\hline 16 & Sulfathiazole [40] & 3 & I & Stable \\
\hline 17 & Sulfamerazine [41] & 2 & I & $\begin{array}{c}\text { Greater tensile strength, } \\
\text { tabletability and compresibility }\end{array}$ \\
\hline 18 & Enalapril maleate [42] & 2 & II & Thermo-chemically stable \\
\hline 19 & Pramocaine [43] & 2 & I & More stable \\
\hline 20 & Diflunisal [44] & 4 & IV & $\begin{array}{l}\text { High crystal density and } \\
\text { intermolecular interactions }\end{array}$ \\
\hline 21 & Chloramphenicol Palmitate [45] & 3 & II & $\begin{array}{l}\text { Thermodynamically stable and } \\
\text { better bioavailability }\end{array}$ \\
\hline 22 & Indomethacin [46] & 3 & I \& II & Higher therapeutic efficiency \\
\hline 23 & Huperzine [47] & 3 & III & $\begin{array}{l}\text { Most thermodynamically stable } \\
\text { under various conditions, higher } \\
\text { solubility than the marketed } \\
\text { formulations }\end{array}$ \\
\hline 24 & Famotidine [48] & 3 & II & $\begin{array}{l}\text { Metastable and commercially } \\
\text { available }\end{array}$ \\
\hline 25 & Efavirenz [49] & 6 & I & More thermodynamically stable \\
\hline 26 & Barbital [50] & 6 & III & $\begin{array}{l}\text { Metastable, high kinetic stability } \\
\text { and commercially available }\end{array}$ \\
\hline
\end{tabular}


silicon oil over a solution (approx. $1 \mathrm{~mL}$; reservoir) containing high concentration of precipitant. Due to higher precipitant concentration, the latter has lower vapor pressure than the drug solution. This results in diffusion of the solvent from the drop towards the reservoir and subsequent crystallization of the API within hours to weeks [45].

\section{Vacuum sublimation}

Sublimation is known to offer excellent crystals of variety of compounds, especially. the air sensitive ones.This approach is frequently employed to induce crystallization with numerous variations of static or dynamic vacuum. A small amount of sample sealed under vacuum in a reactor is generally subject to a temperature gradient in numerous manners. Temperature of the order of $250^{\circ} \mathrm{C}$ can be easily employed at a pressure of around $10^{-2} \mathrm{~mm}$ of $\mathrm{Hg}$. The crystals grow from the wall to the center of the reactor $[43,46]$.

Crystal engineering and supramolecular synthesis (cocrystallization)arebeingused toenhancesolubility, bioavailability, safety and efficacy of various APIs [57]. For instance, glutaric acid co-crystals with 2-[4-(4- chloro-2-fluorophenoxy) phenyl] pyrimidine-4-carboxamide have been developed and possess the marked potential to enhance the bioavailability [58]. Various techniques have been employed to control the polymorphism, like high throughput crystallization method, capillary growth method, laser-induced nucleation, and hetero nucleation on single crystal substrates [8]. High throughput crystallization methods have been developed to screen various conditions like temperature, concentration and solvent combinations. This screening pattern of polymorphs provides an atlas to develop the suitable form [59]. Polymorphs of ritonavir have been developed by high throughput screening methods [60]. Super saturation ratio is an influential parameter for the metastable crystal formation in a solution as well as in capillary. Capillary growth methods are frequently employed techniques to control polymorphism and during the process itself, the crystals can be analyzed in a capillary tube. Nabumetone metastable polymorphs have been reported to be developed by the capillary growth methods [61]. Non-photochemical laser-induced nucleation method has been used in supersaturated solutions of glycine and urea to result in the metastable polymorphs [62-63]. Heteronucleation on single crystal substrates is a crystallization technique used to prepare stable polymorphs by adding polymers in nucleation reaction [64]. Carbamazepine polymorphic form IV has been developed by this method [65].

\section{Characterization techniques}

Various techniques have been used to characterize the polymorphs like thermal analysis (differential scanning calorimetry (DSC), thermogravimetric analysis (TGA)), infrared (FT-IR) spectroscopy, Raman spectroscopy, powder X-ray diffraction (XRD), single crystal XRD, solid state NMR, tetrahertz spectroscopy, optical and electron microscopy, and incoherent inelastic neutron scattering (IINS). Thermal properties of polymorphs are an important aspect and are generally fetched by DSC and TGA [66-68]. Thermal properties of polymorphs are an important aspect and are generally fetched by DSC and TGA [6668]. FT-IR helps to identify the polymorphs by indicating changes in frequencies, relative intensities, band contours and the number of bands. Difference in spectra gives an inference to the internal arrangement of crystals [69-70]. Raman spectroscopy is analogous to FT-IR spectroscopy and is considered an ideal nondestructive tool for polymorphic studies. As far as distinction of various polymorphs and amorphous forms is considered, Raman spectroscopy offers better spectral selectivity [71-72]. $\mathrm{XRD}$ is the most widely employed and reliable technique to identify different crystal phases through different diffraction patterns. Changes in XRD pattern as may be new peak, shoulders, or a shift provides the proof of polymorphic transitions [73]. Single crystal XRD is a nondestructive technique, which provides internal lattice information of crystalline substances, as well as the unit cell parameters like bond length, bond angle and unit cell type [74]. Solid state NMR is a relatively newer, tough powerful

Table 3: Rational for choice/selection of the methods for the preparation of polymorphs [51-56].

\begin{tabular}{|c|c|c|c|c|c|}
\hline S. No. & Method & Characteristics & Advantages & Disadvantages & Pharmaceutical examples \\
\hline 1 & Rota evaporation [51] & $\begin{array}{l}\text { Applicable for high } \\
\text { melting substances }\end{array}$ & High purity and yield & $\begin{array}{l}\text { Desirability of } \\
\text { recrystallization, small } \\
\text { production volume and } \\
\text { expensive }\end{array}$ & Famotidine \\
\hline 2 & $\begin{array}{l}\text { Slow cooling approach } \\
{[52,53]}\end{array}$ & $\begin{array}{l}\text { First choice due to the } \\
\text { ease and simplicity }\end{array}$ & \begin{tabular}{|} 
Large scale \\
production and easily \\
reproducible
\end{tabular} & $\begin{array}{l}\text { Low yield, higher input, } \\
\text { chances of disordered/ } \\
\text { twinned crystals }\end{array}$ & $\begin{array}{l}\text { Sodium chloride, Copper } \\
\text { sulfate }\end{array}$ \\
\hline 3 & $\begin{array}{l}\text { Solvent diffusion } \\
\text { technique [54] }\end{array}$ & $\begin{array}{l}\text { Best for less quantity } \\
\text { of substance and the } \\
\text { materials sensitive to air } \\
\text { and moisture }\end{array}$ & $\begin{array}{c}\text { Larger surface area, } \\
\text { higher solubility, high } \\
\text { mechanical strength } \\
\text { to crystals }\end{array}$ & $\begin{array}{l}\text { Low production yield, } \\
\text { tedious solvent selection }\end{array}$ & $\begin{array}{c}\text { Tolbutamide, Pentacene and } \\
\text { 6,13-Pentacenequinone, }\end{array}$ \\
\hline 4 & $\begin{array}{l}\text { Vapor diffusion } \\
\text { method [55] }\end{array}$ & $\begin{array}{l}\text { Requires less amount of } \\
\text { sample }\end{array}$ & $\begin{array}{l}\text { Less quantity } \\
\text { of sample for } \\
\text { crystallization }\end{array}$ & $\begin{array}{c}\text { Time consuming, difficult } \\
\text { solvent selection, expensive } \\
\text { and low yield }\end{array}$ & Proteins \\
\hline 5 & $\begin{array}{l}\text { Vacuum sublimation } \\
\text { method [53-56] }\end{array}$ & $\begin{array}{l}\text { Desired when quantity } \\
\text { is less and the sample is } \\
\text { thermolabile }\end{array}$ & $\begin{array}{l}\text { Excellent crystal } \\
\text { variety }\end{array}$ & $\begin{array}{l}\text { Disordered or twinned } \\
\text { crystals }\end{array}$ & Haloprogin \\
\hline
\end{tabular}


tool to study crystalline polymorphs, relative crystallinity and amorphous content of pharmaceutical mixtures. This technique provides information about local structure of selected atoms/ nuclei. [44,75]. Terahertz pulsed spectroscopy (TPS) and terahertz pulsed imaging (TPI) are the techniques based on the utilization of the spectral information obtained in the far infrared region of the electromagnetic spectrum. These techniques are now being employed for the physical characterization of pharmaceutical solids. The spectral interpretation and the basic instrumentation are analogous to that of FT-IR and Raman spectroscopy. It gives information on low-frequency intermolecular vibrational modes, which are difficult to be assessed in Raman spectroscopy owing to the closeness of the laser exciting line [76-78]. Optical and electron microscopy provide the visible differences in topography and the structure of the crystal forms [72]. Recently, Tsapatsaris et al. employed IINS for the study of monoclinic and orthorhombic polymorphs of paracetamol and reported interesting findings [79]. Hot stage microscopy part of light microscopy is one of the oldest and powerful techniques to characterize the phase transitions of crystals as well as the optical properties. Temperature variations induced while microscopic view assists in the formation as well as detection of another crystal form(s). Nicotinamide and many more other crystal forms have been successfully studied employing hot stage microscopy [80]. Crystal forms differ from each other in size and shape, and this difference can be easily observed by scanning electron microscopy (SEM) [81].

Crystal structure prediction is a challenging task in crystallography. Computational prediction of polymorphs is many-a-times beneficial in the drug designing, screening of active forms and stable polymorphs as well as other properties including thermodynamics. Zero order models, CCDC (Cambridge crystallographic data centre) and blind tests are the recent computational techniques which are being used to predict the crystal structures [81, 82]. Older and newer aspirin polymorphs have been successfully predicted by these approaches and the newer developed polymorph is relatively more stable and active than the existing one [83-85].

\section{Evaluation Techniques}

\section{Dissolution study}

This study is generally performed in a suitable dissolution medium, generally phosphate buffer saline, $\mathrm{pH}$ 7.4. The timedependent solubility studies are performed and the dissolution profile of various polymorphs is compared. The dissolution pattern can be correlated with the enthalpies of fusion and melting point [86].

\section{Temperature Dependent Solubility of Polymorphs: van't Hoff Plot}

van't Hoff plot is an important approach to determine the values of dissolution enthalpy $(\Delta \mathrm{H})$ and dissolution entropy $(\Delta \mathrm{S})$, as per the equation 2 :

$$
(\text { ln solubility })=-(\Delta H / R T)+(\Delta S / R)
$$

For the same, saturated solubilities at least three temperatures are determined and graph between $\log _{\mathrm{e}}$ of molar solubility and inverse of absolute temperature is plotted. The slope fetches with the enthalpy of dissolution, while the intercept provides the value change in entropy, as per equation $1[48,87]$.

\section{Biological studies}

There are reports on the biological evaluation of the polymorphs in the specific animal model. For instance, Nagaraju et al. prepared polymorphs of famotidine and also evaluated them for antiulcer activity employing pylorus ligation model. They reported better in vivo performance of a particular polymorph vis-à-vis the pure drug [48]. These types of studies are important as they can provide proper understanding about the biological fate alterations owing to the physical form transitions. However, these studies are drug-type specific and are more significant for the stable polymorphic forms.Various physiochemical properties are responsible for failure of compounds in various preclinical and clinical stages. Polymorphic studies are crucial as these forms play a vital role in preclinical/clinical development.

\section{Importance in Pharmaceutical Sciences}

Polymorphism is an influential phenomenon especially in pharmaceutical sciences, as it can significantly influence variety of API properties including flowability, tableting, dissolution rate, solubility, stability and even biological performance including efficacy and toxicity [4, 88-90]. List of a few drugs explored for polymorphic transitions have already been listed in Table 2. Literature is occupied with several examples dictating the influence of physical arrangement on various physiochemical and biological attributes of drugs and excipients. For instance, Wille et al. reported six polymorphs of cocoa butter and all the polymorphs have significantly different melting points. Hence, selection of a particular polymorphic form and prevention of intervention is crucial for development of formulations based on this excipient [91]. Nagaraju et al. prepared polymorphs of famotidine by solvent evaporation method. They reported that PVP polymorphs of famotidine offered better dissolution behavior and antiulcer effect vis-à-vis pure famotidine and its methanol polymorph [51]. Zhang et al. developed two polymorphs of lornoxicam, out of which the form II (orthorhombic form) offered higher solubility and exhibited higher dissolution rate. Henceforth, it was regarded as a better option for oral and injectable dosage forms of the drug [92]. Yadav et al. studied five different polymorphic forms of pefloxacin reported the crystal forms of pefloxacin. Interestingly, all the forms offered high dissolution behavior within $15 \mathrm{~min}$, which was further stabilized to a constant value after 4 hours [93]. Polymorphic forms are established to alter the biological distribution and efficacy of chloramphenicol palmitate [94], phenylbutazone [95], amobarbitol [27], cimetidine[96], 6-mercaptopurine[26] and chlortetracycline hydrochloride[24]; though established in animal models [97]. Despite preclinical studies, various clinical studies employing polymorphic forms of a variety of drugs is easily traceable. Examples include enhanced absorption of chloramphenicol palmitate and comparable bioavailability mefenamic acid polymorphs [98, 99, 97]. For more details, one can refer to the review by Singhal et 


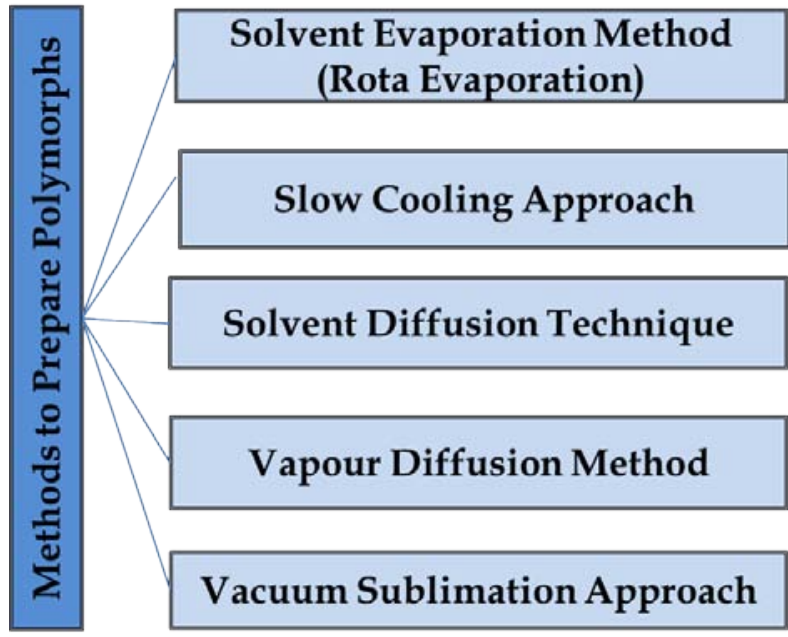

Figure 3: General Methods to Prepare Polymorphs.

al [97]. Taking cognizance to this level of understanding, nowa-days there are serious regulatory concerns pertaining to the physiochemical properties, stability and product performance of the pharmaceuticals prone to show polymorphism. The variations in the outcomes due to polymorphs are more vis-à-vis plain drug, and hence, are demanded to be incorporated in the dossiers being filed to regulatory bodies [100].

\section{Conclusions}

In the present era of evolving understanding, it is accepted that not merely chemical purity/integrity of the API is the sole dependable and formulation influential parameter. The physical arrangements of the constituents' in the crystal lattice have immense potential to influence the physicochemical properties of the drugs and subsequently the therapeutic outcomes. Therefore, the study of polymorphic forms has become as important as any other branch of pharmaceutical sciences, as the former helps to embark upon the proper API/excipient form selection. This understanding will not only enhance the shelf-life of the product, but will help to maintain the potency, as planned/desired. On the regulatory fronts too, now-a-days there are concerns and guidelines to have clarity on the polymorphic transitions of the API as well as the potential excipients and the relevant information is mandatory for filing dossiers with the USFDA and other regulatory/federal agencies. to US-FDA and other federal agencies. Myriad of analytical techniques are available to study these minute transitions which can influence the overall performance of the pharmaceuticals. Simple spectroscopic techniques like FT-IR and Raman can be of the utmost importance. Many varieties of drugs are still unexplored for polymorphism and offer a huge scope for further research in a holistic manner.

\section{References}

1. Karpinski PH. Polymorphism of active pharmaceutical ingredients ChemEngTechnol. 2006; 29(2):233-7. doi: 10.1002/ceat.200500397.

2. Chawla G, Bansal AK. Challenges in polymorphism of pharmaceuticals. CRIPS. 2004; 5:9-12.
3. Guranda DT, Deeva GNG. Drug synthesis methods and manufacturing technologies. Pharm Chem J. 2010; 44:22-28.

4. Li H, Kiang YH, Jona J. Multiple approaches to pharmaceutical polymorphism investigation-a case study. Eur J Pharm Sci. 2009; 38(5):426-32. doi: 10.1016/j.ejps.2009.09.003.

5. Grant D. Theory and origin of polymorphism. In: Brittain H, editor. Polymorphism in Pharmaceutical Solids. 2nd ed. New York: Marcel Dekker Inc; 1999.

6. Lin SY. An Overview of famotidine Polymorphs: solid-state characteristics, thermodynamics, polymorphic transformation and quality control. Pharm Res. 2014; 31(7):1619-31. doi: 10.1007/ s11095-014-1323-5.

7. Qiang W, Kelley K, Tycko R. Polymorph-specific kinetics and thermodynamics of $\beta$-amyloid fibril growth. J Am Chem Soc. 2013; 135(18):6860-71. doi: 10.1021/ja311963f.

8. Rodríguez Spong B, Price CP, Jayasankar A, Matzger AJ, RodríguezHornedo N. General principles of pharmaceutical solid polymorphism: a supramolecular perspective. Adv Drug Deliv Rev. 2004; 56(3):24174.

9. Yu L, Reutzel SM, Stephenson GA. Physical characterization of polymorphic drugs: an integrated characterization strategy. Pharmaceutical Science \& Technology Today. 1998; 1(3):118-127. doi: 10.1016/S1461-5347(98)00031-5.

10.Yu L. Inferring thermodynamic stability relationship of polymorphs from melting data. J Pharm Sci. 1995; 84(8):966-974.

11.Vishweshwar P, Mcmahon JA, Bis JA, Zaworotko MJ. Pharmaceutical co-crystals. J Pharm Sci. 2006; 95(3):499-516. doi: 10.1002/jps.20578.

12. Threlfall T. Polymorphs, solvates and hydrates. Handbook of Vibrational Spectroscopy. 2006. doi: 10.1002/0470027320.s8301.

13. Stahly GP. A survey of cocrystals reported prior to 2000. Crystal Growth \& Design. 2009; 9(10):4212-29. doi: 10.1021/cg900873t.

14. White SP, Cohen C, Phillips Jr GN. Structure of co-crystals of tropomyosin and troponin. Nature. 1987; 325(6107):826-28.

15. Brittain HG. Crystallographic consequences of molecular dissymmetry. Pharm Res. 1990; 7(7):683-690.

16. Easson LH, Stedman E. Studies on the relationship between chemical constitution and physiological action: Molecular dissymmetry and physiological activity. Biochem J. 1933;27(4):1257-66.

17. Llinas A, Goodman JM. Polymorph control: past, present and future. Drug Discov Today. 2008; 13(5-6):198-210. doi: 10.1016/j. drudis.2007.11.006.

18.ICH. ICH harmonised tripartite guideline; Specifications, Test Procedures and Acceptance Criteria for New Drug Substances and New Drug Products, Chemical Substance (Q6A). 1999.

19. Babcock WC, Friesen DT, Nightingale JA, Shanker RM, inventor; Pfizer Products Inc., assignee. Pharmaceutical solid dispersions. European Patent Application EP-1027886A2. 2000 Aug 16.

20. Singhal D, Curatolo W. Drug polymorphism and dosage form design: a practical perspective. Adv Drug Deliv Rev. 2004; 56(3):335-47.

21. Callow RK, Kennard O. Polymorphism of cortisone acetate. J Pharm Pharmacol. 1961; 13(1):723-28. doi: 10.1111/j.2042-7158.1961. tb11899.x.

22. Levi G, Procknal JA. Dissolution rate studies on methylprednisolone polymorphs. J Pharm Sci. 1964; 53:656-658. doi: 10.1002/ jps.2600530617. 
23. Moustafa M, Ebian A, Khalil S, Motawi M. Sulphamethoxydiazine crystal forms. J Pharm Pharmacol. 1971; 23(11):868 - 74. doi: 10.1111/j.2042-7158.1971.tb10205.x.

24. Miyazaki S, Arita T, Hori R, Ito K. Effect of polymorphism on the dissolution behavior and gastrointestinal absorption of chlortetracycline hydrochloride. Chem Pharm Bull. 1974; 22(3):63842.

25. Summers MP, Enever RP, Carless JE. The influence of crystal form on the radial stress transition characteristics of pharmaceutical materials. J Pharm Pharmacol. 1976; 28(2):89-99.

26. Yokoyama T, Umeda T, Kuroda K, Kuroda T, Asada S. Studies on drug nonequivalence. X. Bioavailability of 6-mercaptopurine polymorphs. Chem Pharm Bull. 1981; 29(1):194-99.

27. Kato Y, Kohketsu M. Relationship between polymorphism and bioavailability of amobarbitol in the rabbit. Chem Pharm Bull. 1981; 29(1):268-72.

28. Ragnarsson G, Sjogren J. Compressibility and tablet properties of two polymorphs of metoprolol tartrate. Acta Pharm Suecica. 1984; 21(6):321-30.

29. Kopp S, Beyer C, Graf E, Kubel F, Doelker E. Methodology for a better evaluation of the relation between mechanical strength of solids and polymorphic form. J Pharm Pharmacol. 1989; 41(2):79- 82.

30. Kimura K, Hirayama F, Uekama K. Characterization of tolbutamide polymorphs (Burger's forms II and IV) and polymorphic transition behavior. J Pharm sci. 1999; 88(4):385-91.

31. De Villiers MM, Watt VJG, Lotter AP. Kinetic study of the solid-state photolytic degradation of two polymorphic forms of furosemide. Int J Pharm. 1992; 88(1-3):275-83. doi: 10.1016/0378-5173(92)90325-V.

32. Matsuda R, Akazawa R, Teraoka M, Otsuka R. Pharmaceutical evaluation of carbamazepine modifications: comparative study of photostability for carbamazepine polymorphs by using Fouriertransformed reflection-absorption infrared spectroscopy and calorimetric measurement. J Pharm Phamacol. 1994; 46(3):162-67.

33. Roberts RJ, Payne RS, Rowe RC. Mechanical property predictions for polymorphs of sulphathiazole and carbamazepine. Eur J Pharm Sci. 2000; 9(3):277-83.

34. Matsuda R, Akazawa R, Teraoka M, Otsuka R. Pharmaceutical evaluation of carbamazepine modifications: comparative study of photostability for carbamazepine polymorphs by using Fouriertransformed reflection-absorption infrared spectroscopy and calorimetric measurement. J Pharm Phamacol. 1994; 46(3):162-67. doi: 10.1111/j.2042-7158.1994.tb03770.x.

35. Otsuka M, Onoe M, Matsuda Y. Physicochemical stability of phenobarbital polymorphs at various levels of humidity and temperature. Pharm Res. 1993; 10(4):577-82.

36. Martino DP, Guyot Hermann AM, Conflant P, Drache M, Guyot JC. A new pure paracetamol for direct compression: the orthorhombic form. Int J Pharm. 1996; 128(1-2):1-8. doi: 10.1016/0378-5173(95)04127-3.

37. Nichols G, Frampton CS. Physicochemical characterization of the orthorhombic polymorph of paracetamol crystallized from solution. J Pharm Sci. 1998; 87(6):684-93.

38. Beyer T, Day GM, Price SL. The prediction, morphology and mechanical properties of the polymorphs of paracetamol. J Am Chem Soc. 2001; 123(21):5086-94.

39. Sanders GHW, Roberts CJ, Danesh A, Murray AJ, Price DM, Davies $\mathrm{MC}$, et al. Discrimination of polymorphic forms of a drug product by localized thermal analysis. J Microsc. 2000; 198(2):77-81.

40. Kordikowski A, Shekunov T, York P. Polymorph control of sulfathiazole in supercritical C02. Pharm Res. 2001; 18(5):682-88.

41. Sun C, Grant DJW. Influence of crystal structure on the tableting properties of sulfamerazine polymorphs. Pharm Res. 2001; 18(3):274-80.

42. Eyjolfsson R. Enalapril maleate polymorphs: instability of form II in a tablet formulation. Phamazie. 2002; 57(5):347- 48.

43. Schmidt AC, Senfter N, Griesser UJ. Crystal polymorphism of local anaesthetic drugs. J Therm Anal Calorim. 2003; 73:397-404.

44. Brittain HG, Elder BJ, Isbester PK, Salerno AH. Solid-State Fluorescence Studies of Some Polymorphs of Diflunisal. Pharm Res. 2005; 22(6):999-1006.

45. Lin WQ, Jiang JH, Yang HF, Ozaki Y, Shen GL, Yu RQ. Characterization of chloramphenicol palmitate drug polymorphs by raman mapping with multivariate image segmentation using a spatial directed agglomeration clustering method. Anal chem. 2006L; 78(17):6003-11.

46. Tian W, Lian Y. Surface crystallization of indomethacin below Tg. Pharm Res. 2006; 23(10):2350-55.

47.Zhang Qi, Liye LU, Dai W, Mei X. New Polymorphs of huperzine A: preparation, structures, and physicochemical properties of anhydrous crystal Forms. Mei Cryst Growth Des. 2013; 13(5):2198-207.

48. Lin SY. An Overview of famotidine folymorphs: solid-state characteristics, thermodynamics, polymorphic transformation and quality control. Pharm Res. 2014; 31(7):1619-31. doi: 10.1007/ s11095-014-1323-5.

49. Chadha R, Arora P, Saini A, Jain DS. An insight into thermodynamic relationship between polymorphic forms of efavirenz. J Pharm Pharm Sci. 2012; 15(2):234-51.

50.Zencirci N, Griesser UJ, Gelbrich T, Apperley DC, Harris RK. Crystal polymorphs of barbital: news about a classic polymorphic system. Mol Pharmaceutics. 2014; 6(11):338-50. doi: 10.1021/mp400515f.

51. Nagaraju R, Prathusha AP, Subhash Chandra Bose P, Kaza R, Bharathi K. Preparation and evaluation of famotidine polymorphs. Curr Drug Discov Technol. 2010; 7(2):106-16.

52. Alvarez AJ, Singh A, Myerson AS. Polymorph screening: comparing a semi-automated approach with a high throughput method. Crystal Growth and Design. 2009; 9(9):4181-88. doi: 10.1021/cg900421v.

53. Hye JN, Yoo JK, Duk-Young Jung. Polymorphs of Pentacene and 6,13-Pentacenequinone in Solution and Vapor Phase Growths. Bull Korean Chem Soc. 2010; 31(8):2413-15. doi: 10.5012/ bkcs.2010.31.8.2413.

54. Kovačič B1, Vrečer F, Planinšek O. Spherical crystallization of drugs. Acta Pharm. 2012; 62(1):1-14. doi: 10.2478/v10007-012-0010-5.

55. Yang J, Caprioli RM. Matrix sublimation/recrystallization for imaging proteins by mass spectrometry at high spatial resolution. Anal Chem. 2011; 83(14):5728-34. doi: 10.1021/ac200998a

56. Baldrighia M, DavideBartesaghia, Gabriella C, Roberto G, Pierangelo M, Tullio P, et al. Polymorphs and co-crystals of haloprogin: an antifungal agent. CrystEngComm. 2014; 16:5897-5904. doi: 10.1039/ C4CE00367E.

57. Vishweshwar P, McMahon JA, Peterson ML, Hickey MB, Shattock TR, Zaworotko MJ. Crystal engineering of pharmaceutical co-crystals from polymorphic active pharmaceutical ingredients. Chemical communications. 2005; (36):4601-03. 
58. McNamara DP, Childs SL, Giordano J, Iarriccio A, Cassidy J, Shet MS, et al. Use of a glutaric acid cocrystal to improve oral bioavailability of a low solubility API. Pharmaceutical research. 2006; 23(8):1888-97.

59. Morissette SL, Almarsson Ö, Peterson ML, Remenar JF, Read MJ, LemmoAV, et al. High-throughput crystallization: polymorphs, salts, co-crystals and solvates of pharmaceutical solids. Advanced drug delivery reviews. 2004; 56(3):275-300.

60. Morissette SL, Soukasene S, Levinson D, Cima MJ, Almarsson Ö. Elucidation of crystal form diversity of the HIV protease inhibitor ritonavir by high-throughput crystallization. Proc Natl Acad Sci U S A. 2003; 100(5):2180-84.

61. Chyall LJ, Tower JM, Coates DA, Houston TL, Childs SL. Polymorph generation in capillary spaces: the preparation and structural analysis of a metastable polymorph of nabumetone. Crystal growth \& design. 2002; 2(6):505-10. doi: 10.1021/cg0200311.

62. Garetz BA, Aber JE, Goddard NL, Young RG, Myerson AS. Nonphotochemical, polarization-dependent, laser-induced nucleation in supersaturated aqueous urea solutions. Phys Rev Lett. 1996; $77(16): 3475$.

63.Zaccaro J, Matic J, Myerson AS, Garetz BA. Nonphotochemical, laserinduced nucleation of supersaturated aqueous glycine produces unexpected $\gamma$-polymorph. Crystal Growth \& Design. 2001; 1(1):5-8. doi: $10.1021 / \operatorname{cg} 0055171$.

64. Grzesiak AL, Uribe FJ, Ockwig NW, Yaghi OM, Matzger AJ. PolymerInduced Heteronucleation for the Discovery of New Extended Solids. Angew Chem Int Ed Engl. 2006; 45(16):2553-56.

65. Lang M, Kampf JW, Matzger AJ. Form IV of carbamazepine. J Pharm Sci. 2002; 91(4):1186-90. doi: 10.1002/jps.10093.

66. Yu L. Inferring thermodynamic stability relationship of polymorphs from melting data. J Pharm Sci. 1995; 84(8):966-74.

67. Jayaraman S1, Maginn EJ. Computing the melting point and thermodynamic stability of the orthorhombic and monoclinic crystalline polymorphs of the ionic liquid 1-n-butyl-3methylimidazolium chloride. J Chem Phys. 2007; 127(21):214504.

68. Chadha R, Arora P, Saini A, Jain D S. An insight into thermodynamic relationship between polymorphic forms of efavirenz. J Pharm Pharm Sci. 2012; 15(2):234-51.

69. Brittain HG, Morris KR, Bugay DE, Thakur AB, Serajuddin AT. Solidstate NMR and IR for the analysis of pharmaceutical solids: polymorphs of fosinopril sodium. J Pharm Biomed Anal. 1993; 11(11-12):1063-9.

70. Aboul-Enein HY, Bunaciu AA, Fleschin S. Analysis of mebendazole polymorphs by Fourier transform IR spectrometry using chemometric methods. Biopolymers. 2002; 67(1): 56-60.

71. Croker D M , Hennigan M C, Maher A, Hu Y, Ryder A G, Hodnett B K. A comparative study of the use of power $x$-ray diffraction, raman, and near infrared spectroscopy for quantification of binary polymorphic mixtures of piracetam. J Pharm Biomed Anal. 2012; 63:80-86. doi: 10.1016/j.jpba.2012.01.013.

72. Láng P, Kiss V, Ambrus R, Farkas G, Szabó-Révész P, Aigner Z, et al. Polymorph screening of an active material. J Pharm Biomed Anal. 2013; 84:177-83. doi: 10.1016/j.jpba.2013.06.002.

73. Klug HP, Alexander LE. X-Ray Diffraction Procedures: For Polycrystalline and Amorphous Materials. 2nd ed. Harold P Klug, Leroy E Alexander, editors. Weinheim: Wiley-VCH; 1974.

74.Goldberg I, Becker Y. Polymorphs of tamoxifen citrate: detailed structural characterization of the stable form. J Pharm Sci. 1987; 76(3):259-64.

75. Harris RK. Applications of solid-state NMR to pharmaceutical polymorphism and related matters. J Pharm Pharmacol. 2007; 59(2):225-39. doi: 10.1211/jpp.59.2.0009.

76. Ikeda Y, Ishihara Y, Moriwaki T, Kato E, Terada K. A novel analytical method for pharmaceutical polymorphs by terahertz spectroscopy and the optimization of crystal form at the discovery stage. Chem Pharm Bull. 2010; 58(1):76-81.

77. Taday PF, Bradley, Arnone DD, Pepper M. Using Terahertz pulse spectroscopy to study the crystalline structure of a drug: a case study of the polymorphs of ranitidine hydrochloride. J Pharm Sci. 2003; 92(4):831-8.

78.Zeitler JA, Taday PF, Newnham DA, Pepper M, Gordon KC, Rades T. Terahertz pulsed spectroscopy and imaging in the pharmaceutical setting--a review. J Pharm Pharmacol. 2007; 59(2):209-23.

79. Tsapatsaris N, Kolesov BA, Fischer J, Boldyreva EV, Daemen L, Eckert J, et al. Polymorphism of Paracetamol: A New Understanding of Molecular Flexibility through Local Methyl Dynamics. Mol Pharm. 2014; 11(3):1032-41.

80. Berry DJ, Seaton CC, Clegg W, Harrington RW, Coles SJ, Horton PN, et al. Applying hot-stage microscopy to co-crystal screening: a study of nicotinamide with seven active pharmaceutical ingredients. Crystal Growth and Design. 2008; 8(5):1697-1712.

81. Rodríguez-Hornedo N, Murphy D. Surfactant-facilitated crystallization of dihydrate carbamazepine during dissolution of anhydrous polymorph. J Pharm Sci. 2004; 93(2):449-60.

82. Price SL. The computational prediction of pharmaceutical crystal structures and polymorphism. Adv Drug Deliv Rev. 2004; 56(3):30119.

83. Gavezzotti A, Filippini G. Polymorphic forms of organic crystals at room conditions: thermodynamic and structural implications. J. Am. Chem. Soc. 1995; 117(49):12299-305. doi: 10.1021/ja00154a032.

84. Bond AD, Boese R, Desiraju GR. On the polymorphism of aspirin: Crystalline aspirin as intergrowths of two "polymorphic" domains. Angew Chem Int Ed Engl. 2007; 46(4):618-22. doi: 10.1002/ anie. 200603373 .

85. Withers N. Drug polymorphism: Aspirin headache solved. Nature Chemistry. 2011; 3(11):835-35. doi:10.1038/nchem.1186.

86. Kobayashi Y1, Ito S, Itai S, Yamamoto K. Physicochemical properties and bioavailability of carbamazepine polymorphs and dihydrate. Int J Pharm. 2000; 193(2):137-46. doi: 10.1016/S0378-5173(99)00315-4.

87. Pudipeddi M1, Serajuddin AT. Trends in solubility of polymorphs. J Pharm Sci. 2005; 94(5):929-39.

88. Erdemir D1, Lee AY, Myerson AS. Polymorph selection: the role of nucleation, crystal growth and molecular modeling. Curr Opin Drug Discov Devel. 2007; 10(6):746-55.

89.Savjani KT1, Gajjar AK, Savjani JK. Drug solubility: importance and enhancement techniques. ISRN Pharm. 2012; 195727. doi: 10.5402/2012/195727.

90. Haleblian J, McCrone W. Pharmaceutical applications of polymorphism. J Pharm Sci. 1969; 58(8):911-29.

91. Wille RL, Lutton ES. Polymorphism of cocoa butter. J Am Oil Chem Soc. 1996; 43(8):491-6.

92.Zhang J, Tan X, Gao J, Fan W, Gao Y, Qian S. Characterization of two 
polymorphs of lornoxicam. J Pharm Pharmacol. 2013; 65(1):44-52. doi: 10.1111/j.2042-7158.2012.01573.x.

93. Yadav MR, Shaikh AR, Ganesan V, Giridhar R, Chadha R. Studies on the crystal forms of pefloxacin: preparation, characterization, and dissolution profile. J Pharm Sci. 2008; 97(7):2637-48.

94. Maeda T, Takenaka H, Yamahira Y, Noguchi T. Use of rabbits for absorption studies on polymorphs of chloramphenicol palmitate. Chem Pharm Bull. 1980; 28(2):431-36.

95. Pandit JK, Gupta SK, Gode KD, Mishra B. Effect of crystal form on the oral absorption of phenylbutazone. Int J Pharm. 1984; 21(1):129-32.

96. Kokubo H, Morimoto K, Ishida T, M Inoue, K Morisaka. Bioavailability and inhibitory effect for stress ulcer of cimetidine polymorphs in rats. Int J Pharm. 1987; 35(1-2):181-83.
97. Singhal D, Curatolo W. Drug polymorphism and dosage form design: a practical perspective. Adv Drug Deliv Rev. 2004; 56(3):335-47. doi: 10.1016/j.addr.2003.10.008.

98. Aguiar AJ, Krc J, Kinkel AW, Samyn JC. Effect of polymorphism on the absorption of chloramphenicol from chloramphenicol palmitate. J Pharm Sci. 1967; 56(7):847- 53.

99. Aguiar AJ, Zelmer JE. Dissolution behavior of polymorphs of chloramphenicol palmitate and mefanamic acid. J Pharm Sci. 1969; 58(8):983- 87. doi: 10.1002/jps.2600580817.

100. Raw AS, Furness MS, Gill DS, Adams RC, Holcombe FO Jr, Yu LX. Regulatory considerations of pharmaceutical solid polymorphism in Abbreviated New Drug Applications (ANDAs). Adv Drug Deliv Rev. 2004; 56(3):397-414. 